\title{
Futebol amador e drogas: uma análise a partir do conceito de Outsiders
}

\author{
Amateur soccer and drugs: an analysis from the Outsiders Concept \\ Futbol Amateur y drogas: un análisis a partir del concepto Outsiders
}

Matheus Dias Coelho, Raquel da Silveira ${ }^{\mathrm{II}}$

\begin{abstract}
Resumo
O trabalho trata das relações existentes entre futebol amador e drogas. Para isso, realizamos um estudo qualitativo em que entrevistamos dois jogadores de futebol amador da cidade do Rio Grande/RS. Para a análise utilizamos o conceito de Outsiders proposto por Becker (2008). Questionamos para quem e onde as representações dos jogadores que consomem drogas podem ser consideradas outsiders. Assim, colocamos em debate tanto um discurso 'salvacionista' sobre o esporte quanto um discurso 'causal' em relação ao meio social e quanto ao uso de drogas. Por fim, concluímos que a relação entre o futebol amador e drogas é complexa e envolve inúmeras esferas da vida.
\end{abstract}

Palavras-chave: Futebol; Entorpecentes; Sociologia

\begin{abstract}
The study is about the relation between amateur soccer and drugs. In order to achieve this study, we conducted a qualitative study in which we interviewed two amateur soccer players from Rio Grande City/RS/Brazil. To analyze this, we used the Outsiders concept proposed by Becker (2008). We questioned to whom and where the soccer players' representations, who use drugs, can be considered outsiders. Thus, we debate both a 'Salvationist' discourse about sport and a 'causal' discourse in relation to the social environment and to using of drugs. We conclude that the relationship between amateur soccer and drugs is complex and it involves many spheres life spheres.
\end{abstract}

Keywords: Soccer; Narcotics; Sociology

\footnotetext{
${ }^{\text {I }}$ Universidade Federal do Rio Grande - FURG - Rio Grande, RS, Brasil - endereço: Felizardo, 750, Jardim Botânico, Porto Alegre/RS, CEP: 90690-200- email: matheusdcoelho@ hotmail.com

${ }^{\text {II } U n i v e r s i d a d e ~ F e d e r a l ~ d o ~ R i o ~ G r a n d e ~ d o ~ S u l ~-~ U F R G S ~-~ P o r t o ~ A l e g r e, ~ R S, ~ B r a s i l ~ e-m a i l: ~ r a q u f r g s @ ~ g m a i l . c o m ~}$
} 


\section{Resumen}

El trabajo trata de las relaciones existentes entre el fútbol amateur y las drogas. Para eso, se llevó a cabo un estudio cualitativo en el que entrevistamos a dos jugadores de fútbol amateur de la ciudad de Rio Grande / RS. Para el análisis utilizamos el concepto de Outsiders propuesto por Becker (2008). Se preguntó a quién y dónde las representaciones de jugadores que consumen drogas pueden ser consideradas outsiders. Así, ponemos en debate tanto un discurso 'salvacionista' sobre el deporte como un discurso 'causal' en relación al medio social y cuanto al uso de drogas. Por último, concluimos que la relación entre el fútbol amateur y las drogas es compleja e involucra innumerables esferas de la vida.

Palavras clave: Fútbol; Narcóticos; Sociología

\section{Introdução}

O futebol é um esporte amplamente difundido na sociedade e frequentemente utilizado como ferramenta para implementação de políticas públicas que visam à promoção de saúde e lazer da população, em especial de pessoas em situação de vulnerabilidade social. É facilmente encontrada na literatura acadêmica trabalhos que ressaltam uma vinculação, quase que direta, da prática esportiva com a criação de hábitos saudáveis, dentre os quais a prevenção ao uso de drogas. Pereira e Gorski (2011), por exemplo, acreditam que aqueles que possuem hábitos saudáveis e práticas esportivas no seu cotidiano, assim como, vínculos familiares, sociais e afetivos estruturados estão menos vulneráveis ao uso de entorpecentes. Nesse caso, drogas e esportes estão em lados opostos, ou seja, o esporte remete imediatamente à ideia de hábitos considerados saudáveis, enquanto que as drogas remetem à violência e ao vício.

Também não é difícil encontrar no universo acadêmico pesquisas que evidenciam relações entre práticas esportivas e o uso de drogas. Há desde trabalhos que pautam a noção de dopping esportivo (BALBINOTTI et al., 2005), até os que pautam práticas esportivas realizadas no lazer, em que drogas estão presentes (MYSKIW, 2012). Acessando esses trabalhos, nos deparamos com discursos diferentes dos citados no parágrafo anterior, em que o esporte é visto, a priori, como promotor da saúde e bem estar.

Além disso, a ideia de que a prática de esporte está relacionada a uma conduta saudável e impecável contradizia o observado nos campos de futebol amador da cidade de Rio Grande/RS. Nesses campos identificamos que o uso de drogas e a prática de futebol ganham contornos não opostos. A ideia de um 'futebol que salva' parece contrapor a realidade do futebol amador local, devido a ser comum o consumo de drogas (tanto lícitas quanto não lícitas) pelos jogadores antes e após as partidas. Constituído como um local acolhedor, de interação social, risadas e brincadeiras, de fortalecimento dos laços de amizade, o futebol jogado nos finais de semana também se torna um local de consumo de drogas. Assim, 
consideramos pertinente estudar este espaço. Sendo assim, nosso objetivo é compreender a relação do futebol amador de Rio Grande com o uso de drogas não lícitas, buscando identificar elementos que sustentam essa relação, e assim colocar em debate as compreensões sobre esporte e drogas.

\section{Caminhos investigativos}

Iniciamos esta pesquisa com a realização de observações dos jogos de futebol do campeonato amador da cidade do Rio Grande. As observações aconteceram de maneira não sistemática no ano de 2016. Foram realizadas em finais de semana em que aconteceram jogos do Campeonato Amador da cidade do Rio Grande, totalizando 5 observações. Importante esclarecer que essas observações foram realizadas pelo primeiro autor deste artigo, o qual vivencia o universo do futebol amador de Rio Grande desde 2003 na condição de jogador. Após as observações, procuramos a Secretaria de Município de Turismo, Esporte e Lazer, e realizamos uma entrevista com o superintendente de esporte e lazer do município. Após, fizemos entrevistas com dois jogadores, os quais, durante o período das observações, se mostraram dispostos a participar da pesquisa. Ambos os jogadores assinaram o Termo de Consentimento Livre e Esclarecido. Informamos que esta pesquisa foi aprovada pelo Comitê de Ética em Pesquisa da Universidade Federal do Rio Grande sob o parecer n $n^{\circ}$ 67/2017. Destacamos que optamos pela entrevista semiestruturada, a qual nos possibilitou estabelecer um diálogo em que assuntos diferentes do que os previstos surgiram no decorrer da entrevista. Nas duas entrevistas realizadas assumiu-se um tom de conversa, conforme caracteriza Burgess (1997), em um ambiente informal em que, ao se respeitar a privacidade dos entrevistados, estabeleceu-se um momento em que eles relataram histórias e refletiram sobre situações de suas vidas. O roteiro dessas entrevistas era composto por dois conjuntos de questões: um voltado para a prática do futebol amador ao longo da vida do jogador, e outro relativo ao consumo de drogas, especificamente as psicotrópicas e não lícitas.

As análises das entrevistas seguiram preceitos das pesquisas qualitativas, os quais nos permitiram mostrar a complexidade da relação entre drogas e futebol (TRIVIÑOS, 2008; MINAYO, 1994) a partir da representação dos entrevistados sobre suas histórias e trajetórias. Ao longo da análise sistematizamos as informações a partir de dois eixos: inicialmente sobre a compreensão do futebol amador da cidade de Rio Grande e após sobre as representações dos jogadores entrevistados com o universo futebolístico e o uso de drogas. É a partir dessa sistematização que apresentamos os resultados desta pesquisa. 


\section{Localizando o futebol amador na cidade do Rio Grande}

Atualmente parece ser difícil falar em futebol sem adjetivá-lo. Encontramos na literatura especializada definições de diferentes tipos de 'futebóis'. Damo (2003), por exemplo, classificou o futebol em quatro matrizes: espetacularizado, bricolado, escolar e comunitário. Outra configuração futebolística foi estabelecida por Gonçalves (2002), o qual evidenciou dois níveis de pensamento sobre o futebol, chamados de “jogos abertos e fechados”. Tanto a sistematização proposta por Damo (2003), quanto a proposta por Gonçalves (2002) trazem elementos importantes para compreender o futebol analisado nesta pesquisa. Contudo, parecem carecer de maior flexibilidade, uma vez que o 'futebol amador' que tratamos envolve características que misturam os diferentes tipos de "futebóis"1. Ele é praticado por trabalhadores que às vezes estão presentes e, às vezes, não, ou seja, não são indispensáveis para o jogo acontecer. Existem times equipados e estruturados em que possuem materiais (bolas e uniformes), campo e uma trajetória reconhecida, enquanto outros são constituídos mais recentes em que usam campos emprestados ou alugados e improvisam em seus uniformes. Alguns jogos são filmados, fotografados, outros não. Alguns envolvem uma rede de torcedores, enquanto há jogos que não há ninguém assistindo para além dos próprios times. Enfim, a noção de futebol amador a qual estamos nos referindo se caracteriza por uma complexidade e uma dinamicidade em que enquadrá-la na 'matriz comunitária’ (DAMO, 2003) ou na lógica do ‘jogo aberto’ ou ‘jogo fechado’ (GONÇALVES, 2002) seria reduzir a sua compreensão.

Para ilustrar nosso posicionamento, construímos a Figura 1 que, de maneira esquemática e sintética, expressa o que denominamos de futebol amador.

Figura I: Localização do futebol amador estudado frente aos 'futebóis'

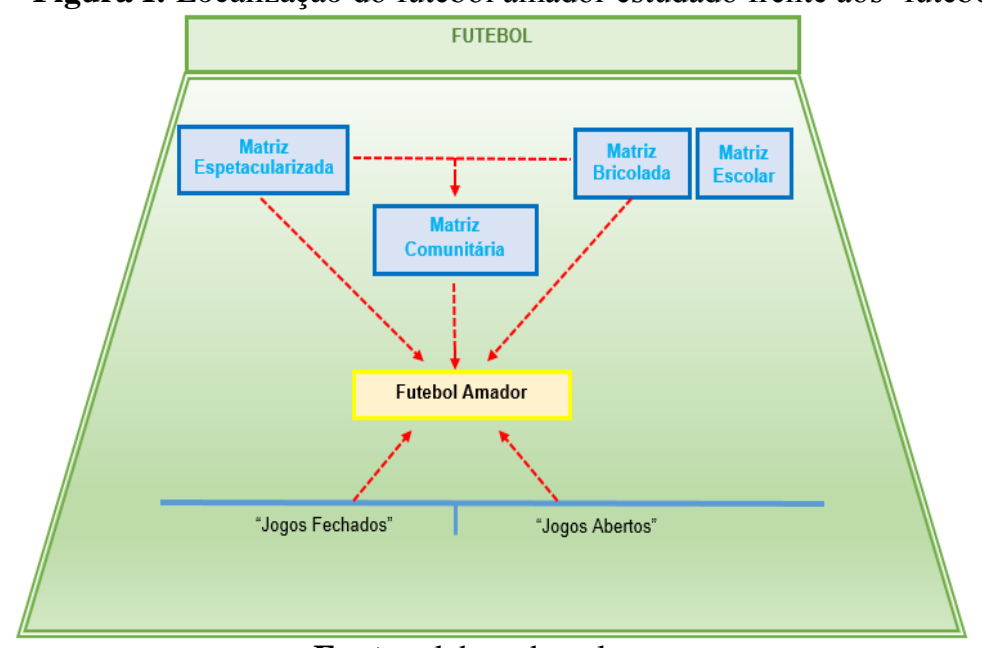

Fonte: elaborado pelos autores

${ }^{1}$ Optamos por utilizar a expressão "futebol amador", por ser o mais utilizado na cidade do Rio Grande. 
$\mathrm{Na}$ cor azul (parte superior da figura) estão descritas as configurações dos diferentes tipos de futebóis conforme classificação em matrizes feita por Damo (2003); na cor preta (parte inferior da figura) estão descritas as configurações dos futebóis conforme Gonçalves (2002); na cor amarela temos a localização do futebol amador que estamos analisando frente aos futebóis, sendo que as setas vermelhas representam possíveis desdobramentos das diferentes configurações que esse futebol assume.

Com essa localização do futebol amador investigado frente aos diferentes 'futebóis', passamos a apresentar algumas informações sobre como ele acontece na cidade de Rio Grande. O Campeonato Municipal de Futebol Amador, criado pela prefeitura da cidade, constituiu o marco inicial em que times da cidade passaram a disputar jogos e estabelecer uma rede de 'conhecidos' do futebol que se encontram nos finais de semana em diversos campos da cidade ${ }^{2}$. Esse evento é organizado, estruturado e dirigido pela Secretaria de Município de Turismo, Esporte e Lazer (SMTEL) de Rio Grande. Nesse campeonato os jogadores circulam por diferentes agremiações de acordo com cada temporada.

As regras utilizadas são as do futebol profissional, porém com algumas particularidades. O Campeonato é organizado em duas categorias: a 'Principal', que corresponde ao primeiro quadro; e a 'Suplente', relativa ao segundo, sendo obrigatória a participação das equipes nas duas divisões. Os times possuem um técnico, dirigentes, massagista. Essas funções são desempenhadas com precárias condições e muitas vezes sem remuneração aos envolvidos. Em relação aos jogadores, essa relação precarizada não é diferente. Muitas vezes, os dirigentes responsáveis pela formação das equipes buscam os melhores jogadores da região e ofertam remunerações que ocasionalmente se materializa via dinheiro e às vezes via chuteiras, roupas, aparelhos eletrônicos.

A Prefeitura é responsável por boa parte das despesas do campeonato, arcando com os gastos referentes à organização, arbitragem e transporte das equipes. Segundo a Comissão Organizadora do Campeonato, as despesas são pagas com dinheiro público, sendo o ‘custo-benefício' satisfatório, já que o dinheiro dos contribuintes está sendo revertido em lazer e entretenimento. Há um grupo no Facebook, com mais 2.000 membros, para divulgações sobre a organização do Campeonato. Através dele são realizadas postagens com as tabelas de jogos, classificação das equipes, resultados das partidas, cartões, goleadores, fotos das equipes e dos jogos.

Em relação aos jogos, estes acontecem aos domingos à tarde e além da presença de integrantes dos times locais e visitantes, muitos familiares, amigos e simpatizantes do esporte comparecem. Podemos

\footnotetext{
${ }^{2}$ Em entrevista com um representante da Secretaria de Município de Turismo, Esporte e Lazer não foi possível identificar qual foi o primeiro ano em que aconteceu esse campeonato, contudo ficou evidente que já se passam mais de 30 anos da sua primeira edição.
} 
afirmar que esses jogos ganham a dimensão de eventos sociais que contam com a participação de pessoas de outras vilas, bairros, cidades ou comunidades. O fato das partidas serem realizadas aos domingos favorece o comparecimento de jogadores e torcedores, sendo que, em paralelo aos jogos, são estabelecidas outras atividades de lazer pelos expectadores, inclusive, pelas crianças. Enfim, o futebol amador não se resume a uma rede de relações masculinas, nem tão pouco aos jogos e competições, mas um tempo/espaço de lazer da comunidade.

Bauler (2005), em uma pesquisa realizada na cidade de Porto Alegre, identificou que a prática do futebol amador agrega os moradores, promove a socialização e interação entre as pessoas. Já, Damo (2003) identifica os campos de várzea como "espaços multiuso, lugares de lazer e recreação das crianças e adolescentes, do chimarrão e das fofocas" (p. 149).

Essa vinculação entre futebol amador e relações de sociabilidade não parece ser algo recente. Em estudo sobre as memórias de um "futebol infame" da cidade de Pelotas, Rigo (2007, p. 83) identificou que as relações de sociabilidade ocorrem no mesmo espaço utilizado para administrar as diferenças e rivalidades existentes entre as equipes, ou seja, essas relações ocorrem no mesmo momento em que a disputa pela vitória do jogo está ocorrendo.

O futebol investigado por nós, que dialoga de maneira bem próxima com as características citadas acima, possui outra peculiaridade que nos chamou a atenção e que se tornou foco do nosso estudo. Assim como encontrado por Myskiw et al., (2014), estar na várzea, fazer parte dela, não significa um distanciamento da família, do trabalho, da política, das tramas da comunidade. Pelo contrário, significa saber lidar com as tramas dessa polifonia e com as sobreposições de agenciamentos ativamente presentes nas reuniões, nas festas, nas excursões e nas rodadas de futebol. Dentre as diversas 'misturas' das esferas cotidianas com o futebol, Myskiw et al. (2014) relatou que em todos os campos pelos quais circulou facilmente notou o consumo de drogas. Essa situação constituía um paradoxo nas vilas, já que, de um lado, o futebol era mencionado como estratégia de combate às drogas. De maneira semelhante, essas práticas foram constatadas nos campos de futebol amador que investigamos.

Assim, para analisar a relação entre futebol amador de Rio Grande com o uso de drogas, nos apoiamos principalmente no conceito de "Outsiders" desenvolvido por Becker (2008). Escolhemos esse conceito pelo seu potencial como ferramenta para analisar os dados elaborados, uma vez que o autor cunha esse conceito a partir do seu olhar para pessoas usuárias de maconha. Para Becker (2008), muito mais que uma questão legal, usar drogas faz parte de uma esfera que a sociedade parece discriminar.

O conceito de outsider tem como referência uma das características da sociedade atual, qual seja, a imposição de regras às pessoas nas mais diversas dimensões de suas vidas. Essas regras visam 
determinar o que é um comportamento apropriado, nomeando em certo ou errado. Nesse sentido, quando uma regra é imposta, aquela pessoa que a infringi, tende a ser rotulada como um outsider, ou seja, "aquele que se desvia das regras do grupo" (BECKER, 2008, p. 17). Em contrapartida, a pessoa outsider pode ter uma opinião diferente sobre determinado assunto. Nesse contexto, "aquele que infringe a regra pode pensar que seus juízes são outsiders" (BECKER, 2008, p. 15). Assim, outsiders não são definidos $a$ priori, mas sim a partir do conjunto de regras e valores que se estabelece como referência.

A seguir apresentamos duas narrativas por nós construídas, a partir das entrevistas com os dois jogadores mencionado anteriormente. Essas narrativas dizem sobre as representações desses jogadores em relação às suas vivências no futebol amador de Rio Grande e em relação ao uso de drogas.

\section{Bigode: outsiders em que espaços e para quem?}

Bigode $^{3}$, em 2017 no momento da entrevista, tinha 22 anos, ensino médio incompleto e atuava profissionalmente como auxiliar de ensaque. Iniciou no futebol amador com 13 anos, e de lá para cá nunca deixou de participar do campeonato amador da cidade. Ele escolhia os times em que jogava, principalmente por afinidade com as pessoas. Na conversa conosco também destacava a importância da torcida, "eu jogo por causa de cada torcedor, porque acaba o jogo e eles vêm te abraçar, te agradecer, porque o que tu faz em campo, é o que alegra eles a semana todinha” (Bigode, 05/08/17).

Geralmente algum amigo o indicava para o diretor de algum time, que podia remunerá-lo ou não, porém o mais importante, segundo ele, eram as relações de amizade. Bigode entendia que mesmo priorizando as relações de amizade ao escolher o time amador a jogar, em alguns casos não se podia confundir a amizade com o jogo. Por se tratar de um esporte competitivo alguns dirigentes dispunham de algumas mordomias aos jogadores em troca de levar mais a sério os jogos no intuito de vencer. No momento que realizamos a entrevista com Bigode, ele integrava um time que disponibilizava uma ajuda de custo para que ele jogasse o campeonato amador.

Segundo as falas de Bigode, o bairro que ele viveu a sua infância e habitava no dia da entrevista era reconhecido pelo do tráfico de drogas, atividade considerada ordinária e de conhecimento de todos que ali circulavam. Nesse bairro, aqueles que usavam drogas não estavam fora do contexto. Inserido nas tramas cotidianas desse bairro, Bigode começou a consumir drogas quando tinha 15 anos de idade incentivado por seus colegas, amigos e irmãos que já eram usuários. Naquela época, apesar de já estar

${ }^{3}$ Para seguir os preceitos éticos da pesquisa, os nome utilizados são fictícios a fim de garantir o anonimato dos informantes. 
inserido no futebol amador, Bigode entendia, refletindo sobre os seus primeiros contatos com drogas, que não sofreu influência do futebol para começar a consumir. A primeira droga que usou foi a maconha, estava junto aos amigos e achou graça, divertido, sentindo-se mais alegre e brincalhão, de forma a estreitar os laços de amizade. Após experimentou a cocaína, inicialmente o consumo se dava esporadicamente e rapidamente passou a sentir necessidade do uso cada vez mais frequente. Para Bigode os efeitos da cocaína são diferentes dos decorrentes do uso da maconha, uma vez que segundos após o consumo ele sente-se "ficar para cima", "esquecendo de tudo", "curtindo o momento" (Bigode, 05/08/17), porém com o passar do tempo a droga parece lhe causar alucinações:

\footnotetext{
tu sente que começa a afetar a tua cabeça, tu sente que parece que está com umas sequelas, está vendo coisas que normal tu não vai ver. Tu tá bem, mas daqui a pouco tu começa, parece que está com coceira no corpo, tu acha que tem alguma coisa que tá te passando, te mordendo, sei lá, só que isso aí. É tudo neurose (Bigode, 05/08/17).
}

Bigode nos conta que nunca traficou e sempre trabalhou para seu sustento. Relatou que nem sempre dispunha do dinheiro para comprar a droga, o que fazia com que muitas vezes ficasse devendo ao traficante. $\mathrm{O}$ dinheiro gasto com a droga passou a limitar os bens que poderiam ser adquiridos pela família. Mesmo assim, se considerava um exemplo para muitas pessoas por já ter a sua casa própria e sua família. Quando realizamos a entrevista com Bigode ele estava desempregado, e essa situação favorecia, segundo sua compreensão, o acesso às drogas, pois estando mais tempo em casa bastava ir à casa de sua mãe ou até um amigo próximo para ser abordado por um traficante que lhe oferecia a droga. Quando conversamos com Bigode, afirmou que consumia maconha e cocaína, sendo a maconha a sua droga preferida e de aceitação no seu ambiente familiar. Pelo fato da maconha não alterar tanto o seu estado de consciência, efeito provocado intensamente pela cocaína, sua esposa não se importava que ele consumisse em casa:

\footnotetext{
tu usa cocaína, tu já não tem controle de nada, tu já não pensa no que tu anda fazendo, tu já não liga pro jeito que tu anda, só pensa no momento naquilo ali. Maconha não, no caso eu chego em casa, eu fumo uma sempre né, aquilo ali acalma, aquilo ali te deixa tranquilizado, sabe. Porque, no caso, dependendo do dia, dependendo de como for a tua rotina, aquilo ali é o que me acalma, e outra coisa, se eu não tenho cocaína, não tenho, não tenho né, mas uma maconha se eu não tenho, já fico estressado (Bigode, 05/08/17).
}

A relação de Bigode com a cocaína também acontecia no espaço do futebol. Ele relatou que o uso da droga dependia da situação, usava, conforme suas palavras, 'quando o corpo pede', seja antes ou após as partidas: “meu corpo tem horas que não me obedece, eu quero só que os meus músculos travam, eu não consigo, entendeu? É algo que tu precisa daquilo ali” (Bigode, 05/08/17). A cocaína parecia oferecer a 
vitalidade muscular necessária para jogar a partida, agindo com uma melhora na performance e habilidade com a bola, como também para reagir ao cansaço ao final do jogo.

A maioria dos 'amigos da bola' e amigos de infância de Bigode estavam associados de alguma maneira ao universo das drogas, seja como usuário ou traficante. Bigode acreditava que as suas amizades, seja no bairro onde morava, seja no futebol, não eram decisivas para determinar o consumo que fazia das drogas, segundo ele o uso era por exclusiva vontade própria. Contudo, estar nesses espaços era uma possibilidade a mais de consumir: "eu penso um pouco só que é uma coisa que mesmo tu querendo sair disso, é algo que tu vai no futebol, é algo que te puxa" (Bigode, 05/08/17). Diz que já pensou em sair das drogas e mesmo sem sucesso após tentar parar afirmou que tem controle sobre seu consumo.

Bigode considerava que, apesar de nos jogos de futebol do campeonato amador as drogas serem facilmente acessadas, a sua principal motivação em jogar eram as relações de amizade que possuía no campo. Relatou que não era preciso ir jogar para ter acesso e usar, pois no seu bairro a qualquer hora ele encontrava drogas, não sendo necessário estar no espaço do futebol para o consumo. Para Bigode, a droga no futebol amador faz parte de outra esfera de sua vida, algo paralelo à sua rotina com as drogas nos arredores do bairro onde morava.

Ao elaborarmos essa narrativa sobre a trajetória de Bigode, identificamos que ele iniciou o consumo de drogas no espaço do seu bairro, sendo o futebol um local paralelo ao consumo. Ao relacionarmos esse caso com a noção de outsider, nos cabe questionar em que espaços e para quem Bigode poderia ser considerado um outsider. Dentro do contexto do seu bairro, ele não estava infringindo regras, pois a droga circulava normalmente, fazendo parte da vida da maioria das pessoas de alguma forma, seja consumindo ou traficando. O uso das drogas no futebol amador era um seguimento do espaço em que cresceu e iniciou sua vida nas drogas. O fato do consumo de drogas ser uma prática recorrente, de acesso facilitado nos jogos e muito comum entre os jogadores, favoreceu o sentimento de pertencimento de Bigode nesse espaço e a estabelecer relações de amizade. Ao olhar para essa narrativa, portanto, nos questionamos: Outsider: Onde? Para quem?

\section{Maroto: um outsider da sociedade}

Maroto, em 2017 no momento da entrevista, tinha 34 anos, ensino médio completo e estava desempregado, porém antes de sua demissão trabalhava como fiscal de transporte coletivo. Inseriu-se no 
futebol amador aos 16 anos por influência das relações de amizade que o convidavam para participar dos times. Jogou também em times profissionais e diz que largou a carreira devido à dependência em drogas.

Antes de usar drogas, Maroto relatou não fumar cigarro e nem beber. Começou a consumir a Cocaína no ambiente do futebol profissional. Segundo ele, quando jogou em um time profissional da cidade foi motivado pela curiosidade e pelo melhor desempenho que observava na maioria dos colegas que usavam a cocaína como uma forma de 'render mais' em campo. Logo esse consumo se intensificou, consumia antes, durante e após os jogos. Assim como Bigode, Maroto nos falou da facilidade de acesso às drogas no universo que ele vivenciava do futebol amador. Lembra que ganhava drogas de torcedores fanáticos pelo time, pois geralmente tinha um torcedor 'Patrão', que pagavam 50 gramas de cocaína por gol e isso o motivava a fazer gols. Na representação de Maroto a cocaína antigamente era uma droga cara, consumida por pessoas com poder aquisitivo mais alto, entretanto naquele momento da entrevista Maroto tinha a compreensão de que o acesso era mais barato e mais fácil. Dizia que nunca ninguém lhe ofereceu droga, mas sim ele se oferecia para usar a fim de experimentar.

Maroto relata que todo dinheiro que ganhava usava para o consumo de drogas, sem adquirir bens materiais, chegando até a não ter o que comer:

eu abria a minha geladeira e não tinha nada, nada, nada, nada pra comer, eu abria os armários aqui e não tinha nada, ficava assim, não tem nada, me escorava no armário e ficava, olhava o prato e me perguntava, o que vou comer agora. É uma vida complicada meu, eu não desejo isso aí pra ninguém, o cara não adquiri nada, bota tudo fora, vou dizer uma coisa pra ti, eu nunca vendi nada, mas tem nego que vende computador, vende tudo meu, vende tudo, tudo (Maroto, 03/08/17).

Nas memórias de Maroto ficaram o registro que ele consumiu drogas por 17 anos e que estava há cinco meses sem usar. Naquele momento da entrevista conosco ele havia sido recentemente convidado por um dirigente a fazer parte de seu time, todavia, pelo fato de ter parado com uso de drogas, estava evitando aceitar o convite por não querer se envolver em situações que facilitassem a sua reinserção no mundo das drogas. Ele compreendia o uso de drogas como algo fora das regras sociais e desempenhava esforço para manter a sua postura em não usar. Ao contrário de Bigode, Maroto acreditava que as relações de amizade influenciavam no seu comportamento e podiam de alguma maneira levá-lo ao consumo. Maroto tentava se manter afastado das drogas, como ele nos relatou, em relação à cocaína:

hoje eu digo pra ti, tô tri bem, tô feliz, só de me levantar e dormir em paz é outra coisa, porque tu não vive, tu vegeta, a droga te toma conta. Imagina tu dormir sempre espiado, achando que a polícia vai vir na tua casa, achando que alguém vai invadir sabe? Não tem dizer assim, eu sei me controlar, vou dar só um dezinho, que é mentira, se tu tem trinta tu gasta trinta, se tu tem quarente tu gasta quarenta, quanto mais dinheiro tu tem, mais dinheiro tu gasta (Maroto, 03/08/17). 
Para conseguir parar de usar drogas Maroto relatava que começou a frequentar uma igreja. Esse ambiente pareceu o ajudar a manter longe do uso das drogas. A sua vinculação com a religião foi incentivada por amigos do futebol amador que também se encontravam na mesma situação. Ele relatou que alguns jogadores o convidavam para ir à igreja, já que eles conseguiram se afastar das drogas.

Lutando contra as drogas, Maroto nos dizia na entrevista que irá começar a fazer a escolha do time por motivo inverso ao anterior, ou seja, iria escolher o time em que a circulação de drogas era pouca ou nenhuma, mesmo que não tivesse remuneração em dinheiro aos jogadores: “...estou fugindo das drogas, o time dos guris ali só vai ir gente boa, os guris tão tudo na benção, claro que tem um ou dois né, não vou dizer que não tem, nem todos tão no caminho do Senhor ainda né, mas vão entrar, vão entrar...” (Maroto, 03/08/17).

Por algum período da vida de Maroto a escolha pelo time a jogar estava relacionada ao dinheiro e às drogas. Ao longo de sua vivência como jogador, as drogas estavam disponibilizadas 'à vontade aos jogadores' e o consumo se dava antes das partidas estendendo-se até o início da mesma e caso sobrasse poderia levar para casa, além de receber uma quantia em dinheiro por ter jogado.

Nas lembranças de Maroto, as drogas chegavam ao espaço do futebol amador, via a 'contratação' de um traficante.Com cerca de 2 a 3 mil reais em drogas o traficante vendia em uma tarde o que ele demoraria 3 dias para vender, pois em média cada jogador consumia cerca de cem a duzentos reais em droga:

cara, era fácil, o que eles iam demorar pra vender em dois, três dias, eles vendiam em uma tarde pra nós, entendesse? Por que todo mundo jogava junto ali. Tinha uns que não usavam cocaína, mas aí fumavam maconha, aí faziam assim ó, leva dois mil de branca e leva mil de maconha, aí aqueles que não cheiravam, fumavam (Maroto, 03/08/17).

Na representação de Maroto, a maioria dos jogadores, dos times de futebol amador da cidade, usavam drogas. Cita um exemplo de um dos times pelo qual passou, em que do total de 23 jogadores apenas 2 não usavam drogas. Ele entendia que os efeitos das drogas melhoravam a vitalidade e desempenho dos atletas durante as partidas, entretanto após o jogo a sensação era de cansaço:

contratavam o "Faísca" e diziam: ô Faísca, leva tanto, leva dois, três mil de droga pros guris por jogo, aí sempre tinha, por isso que nós não perdíamos pra ninguém meu. Nós entravamos a duzentos por hora, mas chegava em casa de noite se arrastando, sem força pra nada meu (Maroto, 03/08/17).

Maroto relatou que chegou ao ponto de frequentar esse espaço exclusivamente pela facilidade no acesso e a gratuidade das drogas, consequentemente o seu consumo. Sentia-se envergonhado perante as 
outras pessoas que já o viram drogado. Em certo momento além de consumir drogas no ambiente do futebol amador ele passou a vendê-las aos times no qual jogava.

Diferente de Bigode que estava inserido em um universo cercado pelas drogas, seja no ambiente em que vivia e frequentava ou nas suas relações sociais, Maroto se via como um outsider da sociedade, pois atribuía o uso de drogas como algo fora das regras:

\begin{abstract}
Olha o que a droga faz contigo, tu te marginaliza perante a sociedade, tu é um ninguém sabe, as pessoas te olham diferente. Tu mesmo, estuda, é uma pessoa boa, mas agora começa a usar droga pra ver que as pessoas que te conhecem vão mudar, qual vai ser a opinião que elas vão ter sobre ti, tu fica marginalizado, é complicado (Maroto, 03/08/17).
\end{abstract}

Ao se sentir um outsider é possível identificar que Maroto despendia esforços na direção de sair dessa situação para igualar-se ao padrão da sociedade atual. As relações sociais fora desse ambiente não o incentivam ao consumo. A religião em que se inseriu e as amizades formadas nesses meios se tornaram importantes ferramentas para Maroto evitar o uso de drogas. Quando Maroto começou a praticar futebol não era usuário de drogas, no entanto na sua representação, a rotina de observar seus colegas usando parece ter o mobilizado a iniciar esse consumo. Dessa maneira, podemos dizer que o ambiente do futebol parece ter sido, ao mesmo tempo, a porta de entrada para Maroto se inserir nas drogas, e a porta de saída a partir do incentivo de alguns jogadores para a vinculação com a igreja.

\title{
6 Considerações Finais
}

Para problematizarmos as relações entre futebol amador e drogas utilizamos o conceito de outsiders de Becker (2008) devido seu potencial esclarecedor em situações onde ocorre o 'desvio' dos padrões de referência. Esse conceito nos ajudou a pensar representações de pessoas que vivenciam o ambiente do futebol amador e as dimensões que as drogas ganhavam nesse espaço e na vida delas.

As representações de Bigode nos fazem compreender que ele não se colocava como um outsider por ser consumidor de drogas, pois estava inserido em um mundo onde o consumo e tráfico de drogas era algo rotineiro, frequente e diário, sendo referência para ele aqueles que usavam drogas ou as vendiam. Em contrapartida, as representações de Maroto nos levam a refletir que o uso de drogas foi iniciado por ele no futebol amador porque se sentia um outsider naquele ambiente, já que a maioria dos jogadores fazia uso. Contudo, após ter se tornado usuário de drogas e frequentar outros espaços em sua vida que não o futebol amador, é possível considerarmos que Maroto se localizou novamente na posição de outsider, dessa vez 
por ser usuário de drogas. Foi então que no mesmo universo do futebol amador, porém em outro núcleo, Maroto encontrou um meio de 'sair' do vício a partir dos colegas de um time que o levaram para a igreja e o incentivaram a parar de usar.

Enfim, ao colocarmos em debate futebol amador e drogas, pudemos compreender que é uma relação bastante complexa. Nesse espaço os vínculos de amizade criados entre as pessoas são muito fortes, o bastante para mobilizar o outro a experimentar droga ou tirá-lo dela, ou seja, esses vínculos podem tanto potencializar ou diminuir as chances de consumir drogas. As representações do uso de droga se vinculavam ao melhoramento do desempenho esportivo, fato valorizado pelos jogadores e que podia influenciar diretamente na decisão de usar ou não antes e durante as partidas, como aconteceu com Bigode e com Maroto. A droga também era posicionada como um objeto para pagamento, uma moeda de troca que norteava muitos jogadores na escolha dos seus times. Nesse sentido, retomando o diálogo que iniciamos na Introdução deste artigo, podemos dizer que os projetos sociais ditos 'salvacionistas' podem alcançar seus efeitos desejados no esporte, entretanto essa pesquisa mostra que essa 'salvação' não é consequência do esporte, pois o que parecer mobilizar esses efeitos são os vínculos e as relações que lá foram estabelecidos.

\section{Referências}

BALBINOTTI, M. A.; BALBINOTTI, C. A.; SANTOS, L.; BARBOSA, M.; JUCHEM, L. Doping no Esporte Problematização Ética. Rev. Bras. Cienc. Esporte, Campinas, v. 27, n. 1, p. 113-122, set. 2005.

BAULER, S. R. G. O futebol faz rolar mais do que uma bola: um estudo sobre o significado do futebol numa periferia urbana. 2005. Dissertação (Mestrado) - Programa de Pós-Graduação em Ciências do Movimento Humano, Universidade Federal do Rio Grande do Sul, Porto Alegre, 2005.

BECKER, Howard S. Outsiders: estudos de sociologia do desvio. Tradução de Maria Luiza X. de Borges. Revisão técnica Karina Kuschnir. 1ª ed. - Rio de Janeiro: Jorge Zahar Ed., 2008.

BURGESS, Robert G. A Pesquisa de Terreno. Uma introdução. Oeiras: Editora Celta, 1997.

DAMO, A. S. Monopólio estético e diversidade configuracional no futebol brasileiro. Movimento. Porto Alegre: v. 9, n. 2, 2003, p. 129-156.

GONÇALVES, A.M.A. Futebol amador: Campo Emergente de Sociabilidade. Fortaleza, Ceará: Dissertação de Mestrado em Sociologia, Universidade Regional do Cariri, 2002.

MINAYO, M. C. de S. Pesquisa social: teoria, método e criatividade. 17ª ed. Petrópolis, RJ: Vozes, 1994. 
MYSKIW, M. Nas Controvérsias da Várzea. Trajetórias e Retratos em um Circuito de Futebol da Cidade de Porto Alegre. Tese de Doutorado da URGS, Porto Alegre, 2012.

MYSKIW M.;STIGGER M.P. O futebol "de várzea" é "uma várzea"!? Etnografia da organização no circuito municipal de Porto Alegre. Revista Movimento. v. 20, n. 2, p. 445-469, Porto Alegre, abr./jun. de 2014.

PEREIRA, D.L.; GORSKI, G.M. A influência do exercício físico no humor em dependentes químicos em tratamento. LECTURAS: Educación Física y Deportes. Buenos Aires: v. 153, p. 1-1, 15, fev. de 2011.

RIGO, L. C. Amizade, pertencimento e relações de poder no futebol de bairro. Revista Pensar a Prática. Goiânia: v. 10, n. 1, p. 83-98, jan/jun 2007.

TRIVIÑOS, A. N. da S. Introdução à pesquisa em ciências sociais: a pesquisa qualitativa em educação. São Paulo: Atlas, 2008.

\section{Como citar este artigo}

COELHO, M. D.; SILVEIRA, R. Futebol amador e drogas: uma análise a partir do conceito de Outsiders. Revista Kinesis, Santa Maria, v. 38, p.01-14, 2020.

* O presente trabalho não contou com apoio financeiro de nenhuma natureza para sua realização. 